Fittipaldi, M. (2021): La representación de la muerte en la poesía de Jacobo Regen. Cultura, Lenguaje y

\title{
La representación de la muerte en la poesía de Jacobo Regen
}

The representation of death in Jacobo Regen's poetry

\section{MARTINA FITTIPALDI}

UNIVERSITAT AUTÒNOMA DE BARCELONA

ORCID: https://orcid.org/0000-0001-6480-0777

RESUMEN: El estudio desarrollado en estas páginas se propone dos objetivos principales: por un lado, analizar cuáles son las representaciones de la muerte halladas en la poesía del escritor argentino Jacobo Regen y, por otro, reconstruir y caracterizar el sujeto cultural presente en la producción poética de este autor. Para ello, se realiza la selección de un corpus de poemas presentes en sus dos libros más reconocidos, Canción del ángel y otros poemas (1971) y El vendedor de tierra (1984), en los cuales se puede rastrear la idea de la muerte en el nivel fenotextual de los poemas a través de aspectos fónicos, semánticos y también visuográficos. Se parte así de estudios previos en torno al análisis discursivo de textos poéticos (Bossi, 2001; Guzmán, 2013, 1992; García, 2015; Verdugo 1982) y se utiliza como método de investigación la perspectiva sociocrítica (Cros, 1997; 2011). Este tipo de aproximación posibilita el hallazgo de un sujeto cultural heterogéneo, atravesado por diversas ideologías que ponen de manifiesto la presencia de múltiples maneras de representación de la muerte en la poesía del autor estudiado, entre las que destaca la que denominamos «microsemiótica del tránsito» que se va construyendo a lo largo de su producción literaria.

Palabras clave: poesía, muerte, representación, sujeto cultural, análisis sociocrítico.

ABSTRACT: The study developed in these pages proposes two main objectives: on the one hand, to analyze which are the representations of death found in the poetry of the Argentinian writer Jacobo Regen and, on the other hand, to reconstruct and characterize the cultural subject present in the poetic production of this author. For this purpose, we selected a corpus of poems from his two most recognized books, Canción del angel y otros poemas (1971) and El vendedor de 
tierra (1984). In these books, the idea of death can be traced at the phenotextual level of the poems through phonic, semantic, and also visuographic aspects. We based on previous studies about the discursive analysis of poetic texts (Bossi, 2001; Guzmán, 2013, 1992; García, 2015; Verdugo 1982), and the socio-critical perspective as a research method (Cros, 1997; 2011). This approach allow us to find a heterogeneous cultural subject, traversed by various ideologies that reveal the presence of multiple ways of representing death in the poetry of the studied author. Among these representations of death, we distinguish one that we call «microsemiotics of transit» which is being built throughout his literary production.

Key words: poetry, death, representation, cultural subject, sociocritical analysis.

\section{INTRODUCCIÓN}

Un poema se parece al suspenso temporal y por lo tanto se parece a la muerte.

No se puede alcanzar todo lo que ese yo dice; pero existe la sensación de que se puede decirlo para siempre. Bossi (2001: 49).

Iniciamos esta investigación preguntándonos: ¿Cómo está representada la muerte en la poesía del escritor argentino Jacobo Regen ${ }^{1}$ ? ¿A qué universo cultural responde cada una de las representaciones de la muerte presente en sus poemas? Dar una posible respuesta a los interrogantes anteriores se convierte entonces en nuestro objetivo. A partir de los antecedentes de investigación (Bossi, 2001; Guzmán, 2013, 1992; García, 2015; Verdugo 1982) y sobre la base del método sociocrítico (Cros, 1997; 2011) intentaremos desandar el camino trazado por esta poesía para descubrir, en el rastreo de elementos mórficos y en el reconocimiento de las zonas de contradicción de la escritura, cuáles son las memorias sociales inscritas en los textos y cómo se acercan a ellas los lectores. De esta manera pretendemos enfocar el trabajo discursivo en función de una construcción de sentidos que nos permita relevar los modos de existencia de los que da cuenta esta poesía que, a pesar de estar situada en el noroeste argentino $^{2}$, no podemos considerar como regionalista. Cabe hallar entonces los vectores que nos ayuden a desentrañar cuáles son las ideologías y posicionamientos del sujeto cultural presente en esta escritura.

\footnotetext{
${ }^{1}$ Jacobo Regen (1935-2019) fue un poeta nacido en la provincia de Salta (Argentina). A lo largo de su trayectoria literaria publicó un total de ocho libros: Seis poemas (1962), Canción del ángel (1964), Canción del ángel y otros poemas (reedición aumentada en 1971), El vendedor de tierra (1984), Poemas reunidos (1992), Antología poética (1996) y Umbroso mundo (2013), una reedición del mismo título publicado en 1971 bajo la cuidada edición de Keko Ferro y Silvia Katz, que incluye además varios textos inéditos y cinco poemas que han sido musicalizados por artistas argentinos como Gerardo Núñez, Gustavo (Cuchi) Leguizamón y Juan José Botelli.

${ }^{2}$ Más allá de las diversas consideraciones geopolíticas de los límites del noroeste argentino, podemos decir que esta región incluye las provincias argentinas de Jujuy, Salta y Tucumán (Guzmán, 2013).
} 


\section{LA ESCRITURA DE JACOBO REGEN: UNA POÉTICA DEL SILENCIO}

La poesía de Jacobo Regen parece signada por la presencia de la muerte. Más aún, esta presencia se observa no únicamente en el plano semántico de la escritura, sino también en el aspecto fónico, figurativo y gráfico, lo que nos lleva a comprender, tal como plantea Cecilia Pisos, que «la poesía es texto literario pero es más que las palabras que la constituyen; la poesía es sonido pero es más que la música a que da lugar; la poesía es imagen pero imagen compleja, de doble filo, sensorial y conceptual a la vez» (Pisos 2019: 226).

Con respecto al nivel visuográfico ${ }^{3}$, descubrimos que los poemas se escriben y se inscriben -son leídos también- luego de un gran espacio en blanco. Los títulos, escritos por completo en mayúsculas, nos conminan a leerlos por separado, a tomarnos un tiempo para resignificarlos. Así, no solo lo dicho en los textos tiene significación, sino también lo callado, ya que como sostiene Cecilia Bajour:

el silencio es un componente vital de la musicalidad y la espacialidad de la poesía. Las pausas al interior y al final de los versos, los blancos diseñados en la configuración espacial de los poemas, la gradación de información en lo que se dice y cómo se lo dice, las opacidades, las figuraciones de lo metafórico y lo metonímico: todo necesita del silencio para entretejer lo dicho con lo no dicho.

(Bajour, 2018: par 14)

Además, aunque en muchos poemas no aparezca desde el plano fenotextual, el tópico de la muerte está presente a menudo, latiendo por debajo, quizá no en lo dicho, pero sí en el decir, en la enunciación, en esos blancos que observamos entre los términos: en lo callado. Podemos definirlo entonces como una presencia subyacente que va construyendo ausencias y estas son las que remiten al espacio del vacío, de la muerte.

Por todo ello creemos que detrás de esta poesía de ritmo claro y aparente simplicidad se esconde una escritura de gran condensación en la que el lector se convierte en el encargado de la tarea de ampliar los campos de significancia. En esta línea Cros (1997) afirma que el texto literario es «el documento que posee la mayor riqueza informativa, aunque sus informaciones sean trasmitidas con formas más o menos complejas. Se trata, como escribía [...] Lotman, de la forma más económica posible de acumular información» (Cros 1997: 142).

Consideramos así que los textos de Jacobo Regen se encuentran enmarcados por el silencio y caracterizados por la condensación. En las páginas siguientes presentaremos el análisis sociocrítico de una selección de textos pertenecientes a sus dos poemarios más reconocidos - Canción del ángel y El vendedor de tierra -, con el objetivo de rastrear en su poesía las distintas representaciones de la muerte, una problemática que se va desplazando a lo largo de la escritura del autor argentino y que constituye lo que, de acuerdo con Cros (Ibid.), podríamos denominar una «microsemiótica» ${ }^{4}$ dentro de su producción poética.

\footnotetext{
${ }^{3}$ En conversaciones personales con el autor cuando todavía vivía, él mismo ha reconocido la gran importancia que le otorga a este plano en su poesía, tal vez por su antiguo oficio de tipógrafo y editor.

${ }^{4}$ Desde la perspectiva sociocrítica se entiende este concepto como un pequeño sistema de relaciones semánticas que produce sentido, es decir, un microespacio de sentido construido al interior del texto mismo.
} 


\subsection{CANCIÓN DEL ÁNGEL: UNA ESCRITURA ENTRE LA ELEVACIÓN Y LA AUSENCIA}

\subsubsection{El poema 3: la muerte como un olvido que resuena y la búsqueda de una trascendencia etérea}

Ante mis ojos, turbios de inmemorial arena,

cobraste ala y figura de un ave fugitiva

remontando en silencio las ilesas alturas.

Aquí debajo, e1 páramo. Ya ni el viento resuena.

Y ahora que en el aire tu corazón deriva,

entre las zarzas quedan raídas vestiduras ${ }^{5}$.

(Regen, 1992: 25)

El texto anterior está constituido por una sola estrofa de seis versos. Como observamos, todos los versos están ubicados gráficamente dentro de la caja del poema, a excepción de una palabra que en el medio del texto parpadea: «resuena». Este guiño de lectura puede servir más adelante - y será por lo tanto retomado - para la construcción del sentido, ya que pensamos, con la sociocrítica (Cros, 1997), que la forma constituye también el sentido de los textos.

Los seis versos que componen el poema poseen rima consonante $\mathrm{a} \mathrm{b} \mathrm{c} \mathrm{/} \mathrm{a} \mathrm{b} \mathrm{c.} \mathrm{La}$ musicalidad que así se construye y el paralelismo fónico establecido llevan también al paralelismo semántico que, como veremos luego, plantea de igual modo una oposición. Los distintos lexemas van llamando la atención del lector como si lo estuvieran guiando en la búsqueda de la significación. Descubrimos entonces los pronombres posesivos («mis», «tus») que nos presentan a los sujetos construidos al interior del poema. «Yo»y «tú» van adoptando características opuestas y nos remiten - por medio de los deícticos a un tiempo y a un espacio dividido en dos, lo cual nos permite organizar el texto de la siguiente manera:

$\begin{array}{ll}\text { yo } & \text { tú } \\ \text { ahora } & \text { (entonces) } \\ \text { debajo } & \text { (arriba) } \\ \text { aquí } & \text { (allá). }\end{array}$

Se establece así una fuerte oposición entre el mundo celeste y el mundo humano.

En cuanto al índice temporal, observamos que todos los verbos del texto poético analizado están en presente a excepción de «cobraste», el único verbo que aparece en pasado. El «yo» parece entonces mirar desde el hoy, desde el ahora, el pasado, ese tiempo en el que el «tú» remontó vuelo. Aquí es la mirada la que organiza el espacio; vemos que en el abajo se encuentran esos ojos que vieron elevarse al «tú» pájaro.

A partir de la caracterización de los ojos - «turbios de inmemorial arena» - es posible establecer una oposición contundente entre esta figura y aquella de «un ave fugitiva» con la que se identifica al «tú». «Arena» puede leerse, por el adjetivo que la acompaña, como un término que lleva en su interior el sema del tiempo, un tiempo «tan antiguo que no hay memoria» de sus comienzos. A este se opone el lexema «fugitiva» que implica «que pasa muy aprisa y como huyendo» ${ }^{6}$.

\footnotetext{
${ }^{5}$ Este poema y el analizado a continuación pertenecen al poemario Canción del ángel incluido en Poemas reunidos (Regen, 1992).

${ }^{6}$ Para las definiciones de los términos utilizamos el Diccionario de la Real Academia Española (2019).
} 
Además, agrupando las palabras del texto y poniéndolas en relación unas con otras $^{7}$, descubrimos que mientras «arena» nos envía al lexema «páramo», «ave» nos remite a «aire». En la configuración de estos dos espacios, el arriba y el abajo, podemos esbozar también la oposición luz vs. oscuridad que se establece entre el tú y el yo poéticos.

Vemos entonces que mientras el tú emprende vuelo hacia «las ilesas alturas», el yo se encuentra abandonado en ese abajo como sitio donde reina el dolor, como desierto donde no hay posibilidad de búsqueda trascendente.

«Zarzas» remite a lo espinoso y por lo tanto amplía este campo semántico del dolor, dolor de saberse anclado en el mundo. Pero si devolvemos a este término su contenido semántico proveniente del discurso bíblico, que puede ser leído como «texto cultural ${ }^{8}$, encontramos que la zarza es el lugar en donde Dios se le apareció a Moisés, en donde este hubo de descalzarse ${ }^{9}$. La zarza entonces puede entenderse como lo que queda del paso de la trascendencia por el mundo, como los despojos de eso que fue infinito.

Al lado de las «zarzas» se encuentran las «raídas vestiduras», huellas de estos despojos que pueden oponerse a «ilesas alturas», tanto en el nivel fónico como en el semántico. Así mientras «raídas vestiduras» puede ser también una metáfora del yo, de lo terrestre y por lo tanto imperfecto, de lo que ha sido destruido, «ilesas alturas» remite no solo a lo celeste sino a la perfección, a lo que no ha sufrido daño ¿Cómo conjugar estas oposiciones, estos campos?

Aquí retomamos esa palabra descubierta al principio del análisis para observar que, en una escritura donde los versos no se atreven a alejarse los unos de los otros, donde la caja del poema parece ser totalmente hermética, una palabra se escapa: «resuena». Este término es el que nos va a permitir establecer una relación entre el yo y el tú, entre sus espacios.

«Resuena» alude a la ausencia, a ese juego de memoria y olvido que se construye en el poema. Es la ausencia, es lo que queda flotando aún sin estar presente, la marca que leemos detrás de las palabras, en esas huellas. Y esta ausencia implica muerte, muerte que, como olvido, como no-existencia, se despliega a lo largo de todo el poemario ${ }^{10}$ mostrándonos a la vez que solo es posible lograr la trascendencia a partir de la elevación ${ }^{11}$.

Por consiguiente, se construye además otra representación que nos llevaría a ubicar a la muerte en la microsemiótica del tránsito.

\footnotetext{
${ }^{7}$ Recuperamos aquí la importancia otorgada por el estructuralismo a los lugares donde se ubican los signos y a las relaciones entre ellos, pues es el lugar que ocupan en el sistema de relaciones el que los define. Observamos además el destacado sitio que poseen las oposiciones binarias, retomadas más tarde por el método sociocrítico.

${ }^{8}$ Cros entiende este concepto como un «fragmento de intertexto de un determinado tipo que interviene [...] en la geología de la escritura» (1997: 25). También lo define como «bien colectivo» o como «modelo infinitamente retransmitido» (Ibid.).

${ }^{9}$ Vemos aquí como «tras la máscara de la subjetividad se ve entonces operar al discurso del sujeto cultural. Ahora bien, ese sujeto cultural, de naturaleza doxológica, legisla, dicta pautas de conducta, designa paradigmas, recuerda verdades basadas en la fe» (Cros, 1997: 17). La cursiva es nuestra.

${ }^{10}$ Nos referimos aquí específicamente a Canción del ángel, pero creemos que esta representación puede ser rastreada en el resto de sus libros en la medida en que, tal como sostiene Teresa Leonardi Herrán, «sus textos [están] atravesados por el temblor metafísico [y] nacen siempre desde la experiencia y de la necesidad» (Leonardi Herrán, 2019: par 5).

${ }^{11}$ Esta idea de trascendencia ubicada en el más allá y a la que solo se puede acceder a partir de la elevación espiritual, podría corresponderse con la concepción de la muerte judeo-cristiana, propia de una lógica occidental, presente en casi todos los textos de Canción del ángel.
} 


\subsubsection{El poema 6: la muerte como un viaje hacia la ausencia}

Pronto es el viaje, ya la despedida.

El cuerpo, y su costumbre, aquí se queda -prenda terrena que a tu amor se aviene-; pero yo soy un ala que te olvida.

(Regen, 1992: 31)

Este texto, formado por una sola estrofa, condensa en dos oraciones el sentido y da continuidad a la microsemiótica analizada en el poema anterior. Aquí, sin embargo, todos los verbos se enmarcan en un presente que establece, gracias a los adverbios «pronto» y «ya», la idea de un futuro inmediato.

No obstante, se reitera la metáfora del ave y se repite la forma de organizar el espacio: el deíctico «aquí» establece por oposición un «allá» que podemos reconstruir como el espacio celeste. En este sitio hallamos nuevamente al yo y al tú como sujetos que, complementariamente, construyen un todo.

Pero a partir de la sinécdoque «yo soy un ala que te olvida» ${ }^{12}$ observamos que ese todo se encuentra fragmentado. El yo se define como una proyección del otro que, sin embargo, está recortada. Es un miembro mutilado, es el testimonio de esa unidad perdida, de ese todo que no puede reconstruirse. Esta imposibilidad, esta fragmentación, y esta necesidad del otro para existir está íntimamente relacionada con la muerte.

La voz poética revela así «una voluntad de existencia que se constituye a través de un reconocimiento del otro y en el otro» (Bossi, 2001: 29). Al no poder ser en el tú, al no poder identificarse con él, el yo descubre la soledad esencial: la disolución.

Las dos palabras de la sinécdoque que tienen carga sémica, «ala» y «olvida», remiten al campo semántico de la ausencia: «ala» encierra la idea de falta de cuerpo, mientras que «olvida» caracteriza a alguien que no tiene memoria. Así, este yo sin cuerpo y sin memoria representa la muerte.

En este texto entonces, a pesar de que no aparece fenotextualmente el tópico que analizamos, vemos cómo se construye una microsemiótica que nos permite descubrir, en el plano del sentido, una forma de representar la muerte como vacío, como ausencia y también como búsqueda especular del yo en el otro.

\subsection{EL VENDEDOR DE TIERRA: ENTRE EL TESTIMONIO Y LA BÚSQUEDA DE TRASCENDENCIA}

\subsubsection{El vendedor de tierra: la muerte como una frontera y un regreso a la naturaleza}

\section{EL VENDEDOR DE TIERRA}
Vuelve del horizonte
cargando tierra negra en sus espaldas.
Cuando llega lo aplauden los jardines
y se emociona el agua.
Y yo le compro tierra, y algún día
me tendrá que vender toda la carga ${ }^{13}$.

(Regen, 1992: 93)

\footnotetext{
12 Debemos recordar aquí que «la sinécdoque de la parte es una forma de omisión, elide el todo [...], produce un vacío en el sintagma» (Bossi, 2001: 148). Este vacío constituye también una forma de muerte.

${ }^{13}$ Este poema y los dos siguientes forman parte del poemario El vendedor de tierra, incluido en Poemas reunidos (Regen, 1992).
} 
No se dice quién. Debemos volver al título del poema para encontrar el sujeto del primer verso. Luego de releer el paratexto, separado por un gran espacio ${ }^{14}$, vemos que este término - «el vendedor de tierra»- nos está remitiendo ya a una lexía familiar pues da cuenta de una práctica cotidiana en la región del noroeste argentino: la de «vender tierra».

Los seis versos que constituyen el poema, entrelazados por encabalgamientos, no tienen rima, pero poseen un ritmo que va construyendo la armonía a lo largo del breve texto. Esta armonía parece hallarse reforzada por la aliteración: «cargando tierra negra...».

El poema comienza con un verbo: «vuelve». Este nos remite al sujeto presente en el título: el vendedor de tierra, que se transforma así, por el uso del verbo, en un sujeto dinámico, que va y viene llevando a cabo su tarea. Este verbo implica, por tanto, una recurrencia que nos lleva a pensar en un proceso de ida y vuelta repetido, constante.

La tierra que el hombre carga es «tierra negra», símbolo de la fertilidad, de la fecundidad, de la vida. Esta idea se amplía en la segunda estrofa con las prosopopeyas «lo aplauden los jardines» y «se emociona el agua», las cuales nos ayudan a imaginar una naturaleza que renace ante la llegada del vendedor de tierra, sujeto al que podríamos caracterizar así como un símbolo de la vida.

Sin embargo, en la última estrofa, estos mismos elementos -el sujeto y la tierraparecen transformarse en símbolo de la muerte. «Toda la carga» adquiere así el sentido de toda la tierra, esa tierra que va a caer encima del «yo» cuando este muera ${ }^{15}$. Esta idea nos permite volver al epígrafe del libro ${ }^{16}$ y relacionar así ambos textos a fin de construir un campo semántico cuya dominante es la muerte.

Cerca de «toda la carga» se encuentra el único tiempo futuro del poema: la perífrasis «me tendrá que vender» que, regida por un futuro perfecto, indica que la acción, aunque no presente, ya es certera, está acabada. La muerte es vista así en el futuro, pero al mismo tiempo se define como un hecho consumado.

Además, en esta última estrofa aparecen dos verbos («compro» y «vender») que rompen con la lógica construida por el poema y hacen ingresar, en el clima de armonía natural presente, la mención a operaciones económicas $\mathrm{y}$, por lo tanto, culturales: humanas. Estos términos, no obstante, se resemantizan y provocan que se resemantice también el valor de la transacción. Esta «compra» y «venta» implican un intercambio donde lo que se intercambia es la vida por la muerte y viceversa. Aquí entra a jugar la metáfora y gracias a ella comenzamos a descubrir cuáles podrían delimitarse como las zonas de contradicción de la escritura.

Volviendo entonces al primer sustantivo del poema - «horizonte»-descubrimos cómo este término nos invita a pensar en aquello no alcanzado todavía por el yo y vemos cómo el lexema cobra pleno sentido y entra en estrecha vinculación con ese «algún día»

\footnotetext{
${ }^{14}$ Decimos «separado por un gran espacio» porque este título y todos los del libro Poemas reunidos (Regen, 1992) están colocados a gran distancia de los textos. Tal vez esto se deba, como afirmábamos más arriba, a la imperiosa necesidad de llamar la atención sobre esos nombres y a la costumbre de utilizar el silencio como marco.

${ }^{15}$ Esta contradicción nos ayuda a descubrir que no debemos caer en la tentación de creer que los signos puede decodificarse de modo unívoco, que hay «un» significado, «una» verdad detrás de cada signo. Es esta concepción la que ataca Jacques Derrida (1998) cuando afirma que no hay significado pleno sino solo «diffèrance», en el sentido de que el significado solamente puede captarse como resultado de un proceso interpretativo.

${ }^{16}$ Este epígrafe pertenece, como el de Canción del ángel, a Else Lasker Schüler y reza así: «Cuando la tierra te cubría cada puñado me enterraba a mí» (Regen, 1992: 5).
} 
del anteúltimo verso. El umbral de lo no alcanzado todavía va a ser traspasado por el yo ese «algún día» en el que reciba toda la carga, toda la muerte.

Sin embargo, en el último verso estos semas de vida/muerte, que al principio parecen ser opuestos, se resuelven: la muerte es nacimiento y viceversa. Esta unidad construida a partir de la contradicción nos permite descubrir una concepción de la muerte asociada con la tierra como engendradora de vida, como renovación. Por consiguiente, la muerte está representada aquí como una zona de pasaje que nos permite regresar a la tierra como lugar del que se parte y hacia donde se vuelve.

Este modo de representación vuelve a aparecer en el poema «Canción» (Regen, 1992: 95), también del libro El vendedor de tierra, donde observamos una humanización de la naturaleza - a través de la figura del árbol - que contrasta con el desamparo del ser humano. Aquí también se hace presente la contradicción: de este modo el ciprés, árbol asociado tradicionalmente con la muerte, se transforma, a partir de las prosopopeyas «me da su áspera mano, / me saluda, sus hojas enternecen / la niebla de mis uñas», en el elemento de la tierra que permite a la persona volver nuevamente a la vida. Se produce así una fusión integradora donde la naturaleza se personifica y el yo se reconoce naturaleza. La trascendencia se logra así por medio de una vida que recomienza en la tierra $^{17}$.

Aunque estas ideas puedan inscribirse también dentro de la microsemiótica del tránsito que venimos analizando, descubrimos que, en realidad, aquí no hay una búsqueda de elevación hacia lo celeste - como observábamos en el libro Canción del ángel sino que la trascendencia está caracterizada como una vuelta al origen ${ }^{18}$.

Consideramos que la génesis de este pensamiento no se identifica con la idea de trascendencia concebida por la lógica occidental, sino con la creencia en una comunión con la naturaleza que permite al hombre hacerse parte de esta y fecundarla, contribuyendo así al nacimiento de una nueva vida.

\subsubsection{Los muertos: la muerte como memoria y testimonio LOS MUERTOS}

\section{Con los ojos velados de sospechas nos miran largamente al despedirse. Y entre las honras y las bendiciones brillan tatuajes de apagados crímenes.}

Ya desde su título, podemos afirmar que este poema está inscripto en la problemática que nos ocupa. Los cuatro versos que lo constituyen pueden ser divididos en dos unidades en cuanto a lo sintáctico-semántico, aunque esa «Y» del tercer verso nos obligue luego a reunirlos, dándoles continuidad. Observamos aquí, como en el primer poema analizado, una estructura sustentada por el paralelismo: participios («velados», «apagados»), verbos («miran», «brillan»), sustantivos («ojos», «tatuajes»/ «honras», «bendiciones» / «sospechas», «crímenes») pueden así ser agrupados.

Pero llama la atención descubrir que el paralelismo no solo está dado en el nivel de las clases de palabras, sino también desde lo fónico y desde lo semántico. Todos los

\footnotetext{
${ }^{17}$ Podríamos preguntarnos para un análisis posterior si el lexema «tierra» tiene o no, en el espacio discursivo de la escritura de Jacobo Regen, valor de ideologema (Cfr. Cros, 1997).

${ }^{18}$ No obstante, esta idea de una vuelta al origen puede ponerse en relación con el poema 13 de Canción del ángel porque ambos textos comparten el deseo del retorno a un tiempo originario, de un regreso a «la dormida fuente / de donde el hilo de mi sangre arranca» (Regen, 1992: 45).
} 
lexemas agrupados entran en relación y así queda configurado un sistema semiótico que podemos esquematizar de la siguiente manera:

Sistema verbal
velados $\quad$ apagados
miran $\quad$ brillan

Sistema nominal
sospechas crímenes
honras

A partir de aquí descubrimos que también en la noción temporal se establece un paralelismo y una oposición entre los verbos en tiempo presente y los participios, que están designando un pasado. Reescribiendo lo enunciado podemos construir las siguientes frases:

Miran ojos velados de sospechas.

Brillan tatuajes de apagados crímenes.

En ellas no solo vemos claramente el paralelismo sostenido en el texto, sino que descubrimos que el término «ojos» puede ser también acercado a «tatuajes» tanto en lo fónico - ambos son los únicos que poseen «j» en todo el texto-, como en lo semántico y también en lo visuográfico ${ }^{19}$. De esta manera, mientras que los participios y un par de sustantivos («sospechas», «crímenes») construyen el campo semántico de lo oculto, de lo no visible, de lo velado; los verbos en presente y el otro par de sustantivos se organizan en torno a los semas de la luz, de la claridad, de lo visible.

Sin embargo, encontramos que los verbos «miran»y «brillan» remiten a los «ojos» y «tatuajes» de los muertos, pero «las honras y las bendiciones» quedan a cargo de ese «nosotros» que aparece en el segundo verso. Vemos entonces que en el poema puede establecerse una relación antitética entre nosotros vs. ellos que podría corresponder a la oposición vivos vs. muertos. Este juego de sujetos poéticos se asocia además a la oposición luz vs. sombra, visible vs. invisible.

Lo que vemos son las honras y las bendiciones realizadas por el nosotros para esos muertos, pero hay en este verso -el tercero- una gran ironía. Esta nos permite descubrir que detrás de lo aparentemente mostrado se esconde lo invisible, los crímenes que ese nosotros ha apagado. Son entonces los ojos que miran y los tatuajes que brillan los encargados de des-ocultar; son los muertos los que develan las miserias de los supuestamente vivos.

Observamos aquí que la muerte está representada como una forma de dar testimonio; los muertos y sus cuerpos son así los lugares donde podemos encontrar las huellas de los crímenes ${ }^{20}$. Detrás de esta representación de la muerte $-\mathrm{y}$ de los muertoscomo testimonio podemos ver que subyace una memoria donde se inscribe el terror, el dolor, lo oculto, y la necesidad del desenmascaramiento, la urgencia de mostrar que en realidad la muerte se esconde del otro lado, del lado de los $\langle\text { vivos }\rangle^{21}$.

Así, estos ojos y tatuajes (que funcionan también como ojos) se transforman en el lugar desde donde es posible dar visibilidad. El lexema tatuaje nos invita así a que lo

\footnotetext{
19 Llama la atención descubrir que puede trazarse una línea recta que va desde «ojos» hasta «tatuajes» recorriendo verticalmente todo el poema.

${ }^{20}$ Creemos que la concepción planteada aquí está asociada con una situación histórica y con una memoria social determinada que puede remitir, en lo genotextual, a la tradición histórica judía y también -por qué no- a la historia argentina.

${ }^{21}$ Más abajo veremos cómo esta representación de la muerte como testimonio da cuenta también de un tránsito, el tránsito hacia la escritura.
} 
pensemos como lo que significa: «marca, escritura sobre el cuerpo $»^{22}$. Esta idea de tatuaje como inscripción, como huella, nos remite también a la escritura. Tatuajes entonces alude justamente al trabajo de la escritura, a ese dar testimonio que implica tomar la palabra, asumirla.

La escritura se concibe así como cuerpo y las palabras como tatuajes, tatuajes que, desde su materialidad, permiten desenmascarar la miseria humana. Esta concepción de las palabras como «huellas» nos remite al poema «Tatuajes» de Jacobo Regen:

Yo creo en las palabras

que son carne y espíritu:

tatuajes repujados

a punta de cuchillo.

(Regen, 1992: 149).

\subsubsection{Nichos: la muerte como negación de una posible trascendencia NICHOS}

Disciplinadamente, todos juntos, uno por uno, todos separados, en viejos trasatlánticos varados regresan de su viaje los difuntos.

(Regen, 1992: 125)

El texto está organizado en una sola estrofa de cuatro versos, como las coplas. Esta estructuración de origen popular, que puede hallarse también en otros poemas de su producción tales como «Cantar» o «Víbora» (Ibid.: 79 y 121) entre otros ${ }^{23}$, puede ser considerada una de las huellas que va dejando en la escritura el sujeto cultural que buscamos develar. Asimismo, estos cuatro versos poseen una rima consonante $\mathrm{a} b / \mathrm{b}$ a, la cual le otorga al texto gran musicalidad, característica también de las coplas populares.

Sin embargo, mientras en el plano formal observamos esta marca, en la selección léxica descubrimos justamente lo contrario, pues entre los términos elegidos abundan los cultismos: «disciplinadamente», «trasatlánticos», «difuntos».

Desde lo fenotextual, y tal como hemos visto en el poema anterior, el texto ya nos está anunciando la presencia de la muerte. El título, «Nichos», nos hace ingresar en este campo semántico y establece, como las entradas de los diccionarios, el término que va a intentar ser definido en el texto por el sintagma «viejos trasatlánticos varados». Este sintagma lleva en sí un término que nos llama la atención: «trasatlánticos». El lexema, junto con el sustantivo «viaje» y el verbo «regresan», construye un campo semántico que alude al movimiento, a la idea de marcha, de desplazamiento.

Por el contrario, el término a definir, «nichos», incluye los semas de orden, estatismo o pasividad y muerte, que se despliegan luego en el poema: así, mientras que «disciplinadamente» $\mathrm{y}$ «uno por uno» hacen referencia al orden y «difuntos» a la muerte, «varados» alude al estatismo, a la inmovilidad.

Vemos entonces que aquí aparece claramente una zona de contradicción en la escritura ya que la representación de la muerte agrupa campos semánticos opuestos:

\footnotetext{
22 Destacamos especialmente este lexema porque consideramos, con Elena Bossi, que «en la lírica, la concentración es tan densa que una sola palabra puede dar el significado del todo» (2001: 83) y creemos que «tatuajes» podría ser considerado el término clave en este poema.

${ }^{23}$ Cabe aclarar aquí que, a través del tiempo, la escritura de Jacobo Regen se va haciendo cada vez más condensada y va adoptando cada vez más este tipo de estructuras cercanas a la tradición poética popular.
} 
movilidad / inmovilidad ${ }^{24}$. Por esta razón consideramos que, si bien podemos afirmar con Zulma Palermo que la muerte «es mirada desde la presencia de una realidad que la inmanentiza para instalarla en el "mundo de abajo" en negación de trascendencia»" (Palermo 1984: 136) ${ }^{25}$, al mismo tiempo debemos reconocer que en este poema se traza nuevamente la microsemiótica del tránsito que venimos rastreando a lo largo del corpus analizado.

\section{A MODO DE CIERRE}

Todas las representaciones de la muerte que hemos ido construyendo a partir de la exploración y reescritura de los poemas analizados en este estudio intentan responder a la pregunta por el sujeto cultural presente en el corpus escogido. Como sostiene Cros,

al texto literario le da sentido, o mejor, lo convierte en sentido [la] instancia ideológica [del] sujeto cultural. En el texto poético leemos lo que somos o aquello que tenemos vocación de ser como sujeto colectivo, los fantasmas que nos asedian o el devenir que presentimos.

(Cros 1997: 130)

De esta manera y a partir del recorrido trazado en estas páginas, podemos descubrir que en los textos de Regen analizados la voz poética está conformada en realidad por muchos acordes. Variadas perspectivas se entrecruzan en la escritura y esta última se transforma así en el lugar de la diferencia y de la contradicción.

En el análisis de sus diferentes producciones, se manifiesta la presencia de distintas representaciones de la muerte. Así, mientras en Canción del ángel la muerte se construye discursivamente como la búsqueda de la luz o de la elevación espiritual, con $E l$ vendedor de tierra esta comienza a asociarse con la tierra como elemento fundante, renovador y vivificador que permite al hombre volver a su origen, entrar en comunión con la naturaleza de la cual forma parte.

Sin embargo, es también en algunos poemas de El vendedor de tierra donde la muerte se representa como una forma de dar testimonio; los muertos y sus cuerpos son así los lugares donde podemos encontrar las huellas de esas «lapidaciones» («Fumador») y «crímenes» humanos («Los muertos»).

Podemos descubrir entonces, a partir de esta escritura, un sujeto cultural que se construye de manera heterogénea, en la medida en que se encuentra atravesado por el pensamiento religioso propio de la cultura judeocristiana y, a su vez, por las creencias que conciben a la tierra como madre, como núcleo de donde el hombre nace y adonde ha de regresar con la muerte. En este sujeto se entrama también la historia, historia que se imprime, re-presentada, en la escritura literaria y que nos muestra la necesidad de testimoniar todos los crímenes sufridos como pueblo judío y, a la vez, como argentinos.

En medio de estas diferencias encontramos, sin embargo, una línea de sentido que puede ser rastreada a lo largo de la producción poética de Regen. Esta es la representación de la muerte que venimos denominando como «microsemiótica del tránsito». Así, podemos decir que en su poesía la muerte está caracterizada como el umbral, la frontera que ha de franquearse para acceder a esa nueva vida, una nueva vida que es, en última instancia, la posibilidad de hacerse uno con el todo, ya sea este material o espiritual.

En este todo podemos leer también al «otro», ese otro que se escapa de la poesía de Jacobo Regen y a quien el yo intenta siempre alcanzar. En esa búsqueda y en ese

\footnotetext{
${ }^{24}$ Podríamos retomar aquí la noción sociocrítica de coincidencia conflictiva (Cros, 1997:147) como elemento fundador del texto cuyo análisis aquí nos ocupa.

${ }^{25}$ Las comillas pertenecen al texto original de Zulma Palermo (1984).
} 
fracaso se descubre la ausencia, la imposibilidad de llegar más allá. Entonces aparece el silencio. Por esta razón, creemos que los textos estudiados son poemas enmarcados por el silencio, que buscan construir desde lo no dicho para que la flecha del sentido sea aún más certera. Así, el lector es el encargado de reconocer y de comprender la importancia de los espacios en blanco configurados en los textos, otorgándoles una carga de significación en tanto representan el silencio, el vacío en el cual se enmarca el poema, que puede entenderse como un recorte, como un fragmento de sentido y de mundo que quiere, sin embargo, alcanzar la totalidad.

En la ausencia, en el silencio de esta escritura, radica también para el lector la dificultad. Aquí se muestra, con mayor intensidad, la imposibilidad de interpretar del todo un texto literario, pues ese plus de sentido que da su razón de ser a la literatura es el que se acentúa en el texto poético y el que nos permite afirmar, con humildad y a la vez con lucidez, que hay límites a la lectura, orillas que bordean la inefabilidad.

Quizá entonces la función crítica sea la que nos permita intuir o vislumbrar que hay algo detrás pero, a pesar de eso, el silencio de la escritura nos impone límites, los mismos límites que la muerte impone a nuestra vida.

\section{REFERENCIAS BIBLIOGRÁFICAS}

Bajour, Cecilia. 2018. «Todo necesita del silencio». Revista Linternas y bosques. Literatura infantil y juvenil. Recuperado el día 18 de octubre de 2020, de https://linternasybosques.wordpress.com/2018/03/06/todo-necesita-del-silenciocecilia-bajour-respiracion-cuerpo-y-pausa-en-la-poesia-infantil-contemporanea/

Bossi, Elena. 2001. Leer poesía, leer la muerte. Un ensayo sobre el lenguaje poético. Buenos Aires: Beatriz Viterbo Editora.

Cros, Edmond. 1997. El sujeto cultural: Sociocrítica y psicoanálisis. Buenos Aires: Editorial Corregidor.

Cros, Edmond. 2011. «Towards a sociocritical theory of the text». Sociocriticism. Vol. XXVI, 1 y 2: 31-47.

Derrida, Jacques. 1998. «La Différance». En Márgenes de la filosofía. Madrid: Editorial Cátedra.

Real Academia Española. (2019). «Fugitiva» e «Inmemorial». En Diccionario de la lengua española. Recuperado el día 20 de octubre de 2020, de https://dle.rae.es/fugitivo

García, Griselda. 2015. «Entierro de muertos, nacimiento de lilas: La muerte en la poesía de T.S. Eliot». En Vendrá la muerte y tendrá tus ojos. Diez miradas diversas sobre poesía y muerte, comp. Enrique Solinas. Buenos Aires: Editorial Ruinas Circulares, 37-46.

Guzmán, Raquel. 2013. Poesía y sociedad. La lírica del NOA: 1960-1980. Salta: EunSa. Editorial de la Universidad Nacional de Salta.

Guzmán, Raquel. 1992. «Regionalidad y textualidad». En 1991. Crítica literaria. Premio municipal de literatura «Luis José Tejeda». Córdoba: Editorial Emcor.

Leonardi Herrán, Teresa. 2019. «Umbroso mundo». Cátedra UNSa. Salta: Universidad Nacional de Salta. Recuperado el día 23 de octubre de 2020, http://iteraturaargentinaunsa.blogspot.com/2019/01/umbroso-mundo.html

Palermo, Zulma. 1984. «III. Los arquetipos fundantes en la poesía de Jacobo Regen». En La región, el país. Ensayos sobre poesía salteña actual. Salta: Comisión Bicameral Examinadora de obras de autores salteños.

Pisos, Cecilia. 2019. «De rimar a mirar: apuntes sobre la emergencia de un género LIJ más inclusivo». En Renovar el asombro. Un panorama de la poesía infantil y 
juvenil contemporánea en español, ed. Adolfo Córdova. Cuenca: UCLM. Ediciones de la Universidad de Castilla La Mancha, 221-241.

Regen, Jacobo. 1962. Seis poemas. Córdoba: Burnichon Editor.

Regen, Jacobo.1964. Canción del ángel. Tucumán: Premio Ricardo Jaimes Freyre.

Regen, Jacobo.1971. Canción del ángel y otros poemas. Salta: Cooperativa Gráfica de Trabajo San Martín.

Regen, Jacobo. 1984. El vendedor de tierra. Salta: Dirección General de Cultura de la Provincia de Salta.

Regen, Jacobo. 1992. Poemas reunidos. Salta: Ediciones del Tobogán.

Regen, Jacobo. 1996. Antología poética. Buenos Aires: Fondo Nacional de las Artes.

Regen, Jacobo. 2013. Umbroso mundo. Colección Memoria cultural. Salta: Fondo Editorial de la Secretaría de Cultura de la Provincia de Salta.

Verdugo, Iber. 1982. Hacia el conocimiento del poema. Buenos Aires: Editorial Hachette. 